\title{
Capacity building for universal eye health coverage in South East Asia beyond 2020
}

\author{
Taraprasad Das $\mathbb{D}^{1} \cdot$ Jill Keeffe $^{1} \cdot$ Sobha Sivaprasad $^{2} \cdot$ Gullapalli N. Rao $^{1}$
}

Received: 29 January 2020 / Revised: 30 January 2020 / Accepted: 30 January 2020 / Published online: 10 February 2020

(c) The Author(s), under exclusive licence to The Royal College of Ophthalmologists 2020

\begin{abstract}
Background The World Report on Vision suggests that universal eye health coverage (UEHC) can be achieved through an integrated people-centered eye care (IPCEC) delivery. This study provides an estimation of capacity building of facilities and workforce to attain UEHC through IPCEC in South East Asia (SEA) beyond 2020.

Methods The data sources on the magnitude of blindness and visual impairment in the SEA region included reports of the Vision Loss Expert Group, most recent population-based studies from the member states and unpublished data from the study teams. The model is based on the estimated or projected population of the member states in 2020 and 2030.

Results Data from the ten member states of the World Health Organization (WHO) SEA show that the magnitude of blindness and moderate to severe visual impairment (MSVI) has decreased between 1990 and 2015, but still higher than global average. Cataract and uncorrected refractive errors were the common causes of blindness and MSVI, respectively. The estimated WHO SEA region share of world population is likely to increase from 38.39\% in 2020 to $44.32 \%$ in 2030 , and so also will be the visually impaired people. By adopting the IPCEC the WHO SEA countries would require at least 429,802 community workers, 164,784 allied ophthalmic personnel and 10,744 ophthalmologists in the public facilities in 2030 .
\end{abstract}

Conclusion In order to attain UEHC and use the IPCEC model, each country in the region should invest substantially more in structured eye care delivery and workforce.

\section{Introduction}

The World Health Organization (WHO) released the World Report on Vision (WRV) in October 2019 [1]. This report has captured both achievements and shortfalls in eye health delivery over the last four decades, and calls for action to make eye care equitable and universal in delivery, and integrated within the general health system. One of the important recommendations of the WRV is delivery of care through integrated people-centered eye care (IPCEC).

Supplementary information The online version of this article (https:// doi.org/10.1038/s41433-020-0801-8) contains supplementary material, which is available to authorized users.

Taraprasad Das tpd@lvpei.org

1 LV Prasad Eye Institute, Hyderabad, India

2 NIHR Moorfields Biomedical Research Centre, Moorfields Eye Hospital, 162 City Road, London EC1V2PD, UK
The WRV defines IPCEC as "services that are managed and delivered so that people receive a continuum of health interventions covering promotion, prevention, treatment and rehabilitation to address the full spectrum of eye conditions according to the needs, coordinated across the different levels and sites of care within and beyond the health sector, and that recognizes people as participants and beneficiaries of these services throughout their life course". The concept of IPCEC is derived from WHO's integrated peoplecentered health services (IPCHS) 2016-2026 (World Health Assembly, WHA 69.24) [2]. The WRV adopted four of the five suggested strategies of IPCHS which are: (1) empowering and engaging people and communities; (2) reorienting the model of care; (3) coordinating services within and across sectors; and (4) creating an enabling environment. [The fifth strategy of IPCHS was "strengthening governance and accountability"] The IPCEC is designed to deliver universal (eye) health coverage (UHC) and primary (eye) care. UHC advocates equity, quality and protection from financial risk [3]. Primary health care provides appropriate, accessible, and affordable care that meets 
patients' eye care needs in a comprehensive and competent manner [4].

The proposed four levels of care in the WRV include eye care delivery at the community (delivered at homes, schools and other community settings), at the primary health centers (integrated and coordinated in primary care), at the secondary health centers (integrated and coordinated in hospital in- and out-patient settings), and at the tertiary health centers with specialized care [1]. Suggestion for a fifth tier, the advance tertiary care, has been made from India [5].

This report examines the current eye disease burden and forecasts the essential needs of the WHO South East Asian countries for the IPCEC model of eye care delivery in the coming decade.

\section{Methods}

The information on the burden of vision loss was obtained from two main sources: reports by the Vision Loss Expert Group (VLEG) of the Global Burden of Disease (GBD) and the latest population-based study from each country that has conducted population-based surveys in the WHO South East Asia (SEA) region. This information included the current and estimated eye disease burden, the national eye health policy, infrastructure and the eye care workforce. References were sourced from PubMed and Embase using the keywords "blindness", "MSVI", "vision impairment", "south east Asia" and "south Asia" from January 2010 to December 2019.

The GBD study began in 1990 as a World Bank commissioned project to quantify the health effects of more than 100 diseases and injuries across the world to estimate the morbidity and mortality by age, gender and region [6]. By 2015, it had swelled to 1870 researchers pooled from 127 countries with data covering 195 countries. The GBD also introduced the "Disability-adjusted life year" (DALY), a "measure of overall disease burden expressed as the number of years lost due to ill health, disability or early death" as a new metric to quantify the burden of diseases and injuries [7].

The VLEG is an international group of ophthalmologists, optometrists and public health researchers with expertise in ophthalmic epidemiology. This group with 10 core member organizations from 7 countries (Australia, Germany, India, Singapore, South Africa, United Kingdom, United States of America) provided the GBD with epidemiological estimates of blindness and visual impairment (VI), and assisted in calculating DALYs attributable to vision loss. Over years, the VLEG has created a Global Vision Database - an extremely comprehensive database of population-based prevalence eye surveys, dating from 1980 to 2014 [8].
The WHO SEA region consists of 11 countries (Bangladesh, Bhutan, Democratic People's Republic of Korea [DPR Korea], India, Indonesia, Maldives, Myanmar, Nepal, Sri Lanka and Timor-Leste). The International Agency for the Prevention of Blindness SEA works with respective country Ministries of Health, the WHO SEA regional office (WHO SEARO), national non-government organizations (NGO) including VISION 2020: the Right to Sight, and international NGOs, to generate data on blindness and VI, and health system strengthening in the country.

The VLEG collected evidence from country-specific population-based prevalence studies, many of which used the rapid assessment of avoidable blindness method (RAAB) [9]. All publications used the WHO criteria of blindness and VI: Blind - visual acuity $<3 / 60$; Severe VI (SVI) - visual acuity $>3 / 60$ to $<6 / 60$; Moderate VI (MVI) visual acuity $>6 / 60$ to $<6 / 18$; Early VI (EVI) - visual acuity $>6 / 18$ to $<6 / 12$ [10]. In many instances, SVI and MVI were grouped and called moderate to severe VI (MSVI).

\section{Estimation of the numbers of eye care facilities and eye health workforce}

The WRV does not specify the population coverage at each level of eye care from community to tertiary levels. We used the suggestions of the Government of India's concept on community care through a Health and Wellness Centre (HWC) for 5000 people [11] and L V Prasad Eye Institute's (LVPEI, Hyderabad, India) integrated eye health pyramid consisting of primary center serving 50,000 people; secondary center serving 500,000 people, tertiary care serving 5 million people $[5,12]$. The numbers of eye care facilities were calculated as per the population of the country; the workforce was calculated using the LVPEI model described in detail earlier [13]. In brief, the essential functions and the work force needed for each facility is shown in Table 1.

\section{Results}

In the period, 2012-2018, the VLEG group published 33 papers of global and regional data. Eighteen of them dealt exclusively on the analysis of blindness and VI and four of them were on the South or SEA region. The VLEG enumerated six important causes of vision impairment and blindness: uncorrected refractive error, cataract, macular degeneration, glaucoma, diabetic retinopathy and trachoma. The country division in the VLEG group is different from the WHO SEA group of countries. VLEG South East Asia consists of six WHO SEA countries (Indonesia, Maldives, Myanmar, Sri Lanka, Thailand and Timor-Leste) and VLEG South Asia consists of four WHO SEA countries 
Table 1 Structure and function of eye care in a pyramidal model.

\begin{tabular}{lll}
\hline Eye care facility & Essential functions & Eye health personnel \\
\hline $\begin{array}{l}\text { Community catering to } \\
5000 \text { people }\end{array}$ & $\begin{array}{l}\text { Advocacy } \\
\text { Eye screening in adults }\end{array}$ & Community worker-1 \\
Primary catering to & $\begin{array}{l}\text { Eye screening } \\
\text { Refraction } \\
\text { S0,000 people }\end{array}$ & AOP-2 \\
& $\begin{array}{l}\text { Refer } \\
\text { Comprehensive eye exam }\end{array}$ & \\
Secondary catering to & $\begin{array}{l}\text { Community screening } \\
\text { Surgery of common disorders }\end{array}$ & AOP-14 \\
& $\begin{array}{l}\text { Cedical care of glaucoma \& diabetic } \\
\text { retinopathy }\end{array}$ & ophthalmologist-2 \\
& Secondary level care + & \\
& Eye surgery in all disorders & AOP-40 \\
Tertiary catering to 5 & Corneal Transplant & Comprehensive \\
million people & Low vision \& Rehabilitation & Specialist Ophthalmologist-10 \\
& Training \& Clinical research & \\
\hline
\end{tabular}

$A O P$ allied ophthalmic personnel.
(Bangladesh, Bhutan, India, Nepal). DPR Korea, part of WHO SEA, is not part of VLEG South or South East Asia. We included the latest population-based prevalence study from each of the WHO SEA countries (except DPR Korea); seven studies have been published and we collected the other three unpublished data from the study principal or coinvestigator.

VLEG reported that there were 32.4 million people blind and 191 million people with MSVI in 2010 [14]. In 2015, 36 million people were blind, 216.6 million people had MSVI, and 217 million had impaired near vision; 89\% vision-impaired people lived in low- and middle-income countries (LMIC) and 55\% of visual impaired people were female [15]. Table 2 lists the VLEG reported trend of blindness and MSVI in the region and the world between 1990 and the estimates for 2020 [16-19]. This shows that the prevalence of both blindness and MSVI has decreased over the decades in the region, but still higher than the world average. Recent studies show the distribution of age and sex standardized blindness and VI by major ophthalmic disorders in the WHO SEA region (Table 3) [20-26] By far, cataract was the commonest cause of blindness and SVI, and uncorrected refractive error was the commonest cause of EVI and MSVI. Only Myanmar and Nepal reported prevalence of trachoma; it is still a blinding disorder in Myanmar and Nepal is currently free of trachoma [27].

Table 4 shows the suggested permanent eye care facilities as per the population density for each level of service in the eye health pyramid $[5,12]$ for the estimated and projected population in 2020 and 2030, respectively $[28,29]$. Minimum eye health workforce need was calculated as suggested by us earlier [13]. These estimations suggest that by 2030, the WHO SEA region would need a minimum of 429,802 community, 43,374 primary, 4334 secondary and 434 tertiary care facilities. Highest resources would be required in India. Table 5 shows the services that can be delivered in each level. The region would need a minimum workforce of 429,802 community workers, 164,784 allied ophthalmic personnel (AOP) and 14,744 ophthalmologists of which $70.5 \%$ would be comprehensive ophthalmologists (Table 4). The workforce structure shows how there is an unmet need for trained ophthalmologists in many smaller countries, and the urgent need to train more AOPs as they can be supervised to provide a considerable number of services at every level. The estimate of individual country level minimum workforce need is shown in Supplementary Table 1.

\section{Discussion}

Largely owing to the efforts of both service and advocacy in the government and non-government sector in every country, the magnitude of blindness has reduced globally and in the SEA region [30, 31]. The VLEG reported a decrease in global blindness from $0.75 \%$ in 1990 to $0.48 \%$ in 2015 (56.25\% decline) and the global MSVI from 3.83\% to $2.90 \%$ ( $24.28 \%$ decline) [15]. Despite this decrease, the absolute number of blind people increased from 30.6 million in 1990 to 36.0 million in 2015 (17.6\% increase) and the number of people with MSVI increased from 159.9 million in 1990 to 216.6 million in 2015 (35.5\% increase) [32]. This increase was mostly attributed to population rise and growth of ageing population [33]. The estimated WHO SEA population is $38.39 \%$ of world population in 2020 (2995.5 million of 7.8 billion world population) and is expected to increase to $44.32 \%$ (3768.95 million of 8.5 billion of world population) [28, 29].

The VLEG also reported an unequal distribution of blind and visually impaired people in the world. VLEG South 


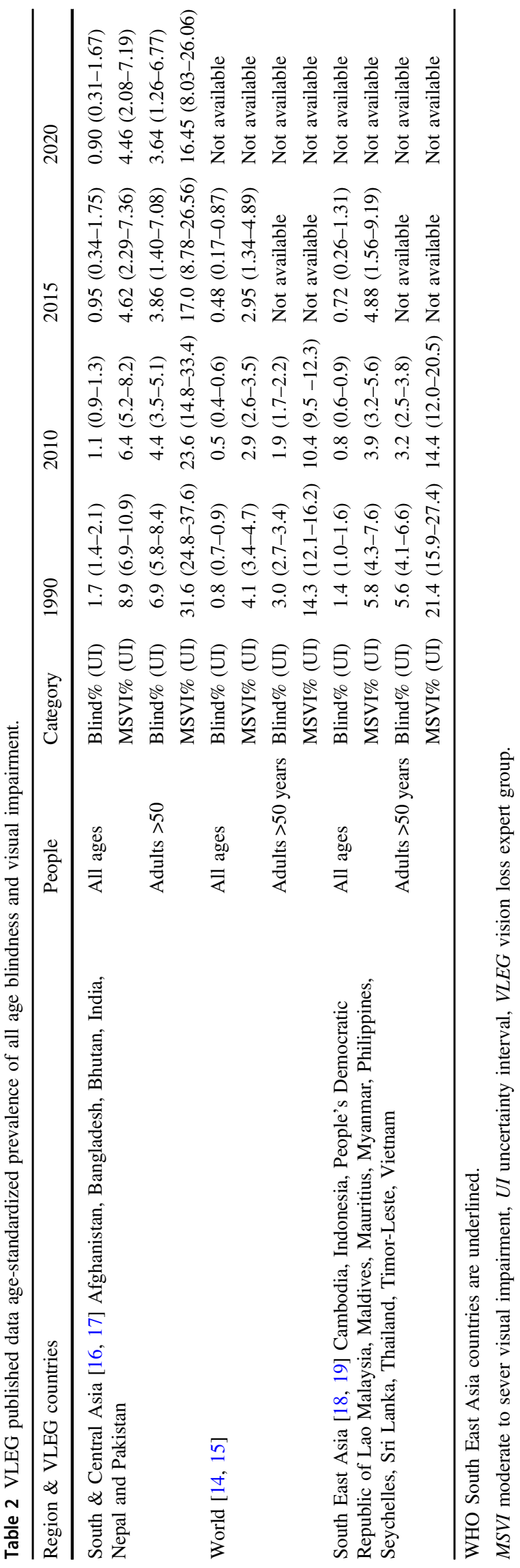

Asia consisting of eight countries (Afghanistan, Bangladesh, Bhutan, Maldives, Nepal, India, Pakistan and Sri Lanka) had the highest magnitude and number of people blind or with MSVI in the adult population aged 50 years or older (magnitude: global 3.38\%, South Asia 5.74\%; blind: 11.76 million people, $32.6 \%$ of world; MSVI: 61.19 million people, $38.3 \%$ of world) [34]. The problem is compounded due to inadequate eye health workforce, and unequal distribution between the urban and rural populations. The three main cadres of human resources in eye care service delivery are ophthalmologists, optometrists and AOP. AOP include ophthalmic assistants, ophthalmic technicians, ophthalmic nurses and opticians. While much of the technical work can be done by AOPs allowing the ophthalmologists to devote quality time in dealing with complex ophthalmic problems and surgery, the AOP cadre is not accredited in some of the SEA countries [35]. The challenge is further increased because of difficulty in accessibility and affordability within the population [36].

One of the solutions lies in the structured delivery of eye care appropriate for the location and the population. The proposed four levels in the IPCEC include eye care delivery at community, and from the primary to tertiary health centers. The framework of IPCEC is derived from the WHO global strategy on "IPCHS" 2016-2026 (World Health Assembly resolution, WHA 69.24) [37]. The stated vision of IPCHS is "a future in which all people have access to health services that are provided in a way that responds to their life course needs and preferences, are coordinated across the continuum of care and are safe, effective, timely, efficient and of acceptable quality".

Delivery of primary care at the community level, integration within the general health system, appropriate referral to the next level of care needs a health system planning, workforce rearrangement, and a conductive government policy. The new health policy of the Government of India to set up HWCs that cover 3000-5000 people could be a model of eye care at community level that is integrated within the general health system [38]. The HWC has all the components of IPCEC community care, but a seamless referral system from the community to tertiary care is needed to be effective and people centered. Based on the recommended workforce at different levels [5], a structured care model is needed for the common avoidable ophthalmic disorders by the IPCEC delivery of care (Table 5). The WRV suggested four-tier structure would work well in less populated country, lesser than 50 million population (five of ten countries in the region, Bhutan, Maldives, Nepal, Sri Lanka and Timor-Leste). We would suggest an additional layer, the advanced tertiary care, in countries with population excess of 50 million (other five of ten countries in the region, Bangladesh, India, Indonesia, Myanmar and Thailand) (Fig. 1). 
Table 3 Distribution of age and sex standardized blindness and visual impairment in ophthalmic disorder of adult population in WHO SEA region by last publication.

\begin{tabular}{|c|c|c|c|c|c|c|c|c|c|}
\hline \multirow[t]{2}{*}{ Country } & \multirow{2}{*}{$\begin{array}{l}\text { Publicatio- } \\
\text { n year }\end{array}$} & \multirow[t]{2}{*}{ Study type \& elements } & \multirow[t]{2}{*}{ Quantity } & \multicolumn{6}{|c|}{ Percentage } \\
\hline & & & & URE & Cat & Glaucoma & $\begin{array}{l}\text { Posterior } \\
\text { segment }\end{array}$ & Trachoma & All causes \\
\hline \multirow[t]{4}{*}{ Bangladesh [20] } & \multirow[t]{4}{*}{2016} & \multirow{4}{*}{$\begin{array}{l}\text { RAAB; } 8 \text { districts } \\
433 \text { clusters } \\
50+\text { years; } 21,596 \text { people }\end{array}$} & Mild & & & NA & & Not reported & NA \\
\hline & & & Moderate & & 33.3 & NA & 2.1 & Not reported & 16.1 \\
\hline & & & Severe & 14.0 & 73.6 & NA & 8.5 & Not reported & 3.5 \\
\hline & & & Blind & 1.1 & 75.8 & NA & 13.0 & Not reported & 2.2 \\
\hline \multirow[t]{4}{*}{ Bhutan [21] } & \multirow[t]{4}{*}{2019} & \multirow{4}{*}{$\begin{array}{l}\text { RAAB, entire country } \\
101 \text { clusters; } \\
50+\text { years; } 4970 \text { people }\end{array}$} & Mild & 46.7 & 34.3 & 0.9 & 7.7 & Not reported & 7.6 \\
\hline & & & Moderate & 5.0 & 65.3 & 3.5 & 17.9 & Not reported & 5.0 \\
\hline & & & Severe & 7.1 & 57.1 & 0.0 & 16.7 & Not reported & 0.6 \\
\hline & & & Blind & 1.5 & 53.8 & 12.3 & 13.8 & Not reported & 1.0 \\
\hline \multirow{4}{*}{$\begin{array}{l}\text { India } \\
\text { (unpublished) }\end{array}$} & \multirow[t]{4}{*}{2019} & \multirow{4}{*}{$\begin{array}{l}\text { RAAB, entire country } \\
31 \text { districts; } \\
85,135 \text { people } \\
50+\text { years- blindness } \\
\& \text { VI } \\
0-49 \text { years- blindness } \\
\& \text { VI }\end{array}$} & Mild & 70.6 & 23.9 & 0.3 & 1.3 & Not reported & 12.92 \\
\hline & & & Moderate & 18.8 & 70.2 & 0.7 & 3.5 & Not reported & 9.81 \\
\hline & & & Severe & 1.5 & 80.7 & 0.8 & 5.2 & Not reported & 1.96 \\
\hline & & & Blind & 0.1 & 66.2 & 5.5 & 7.8 & Not reported & 1.99 \\
\hline \multirow{4}{*}{$\begin{array}{l}\text { Indonesia } \\
\text { (unpublished) }\end{array}$} & \multirow[t]{4}{*}{2017} & \multirow{4}{*}{$\begin{array}{l}\text { RAAB, } 15 \text { Provinces, } \\
917 \text { clusters, } \\
50+\text { years, } 44,855 \text { people }\end{array}$} & Mild & 57.0 & 32.8 & 0.2 & 3.6 & Not reported & 11.3 \\
\hline & & & Moderate & 23.8 & 64.0 & 0.6 & 5.0 & Not reported & 9.1 \\
\hline & & & Severe & 8,5 & 81.4 & 0,3 & 1,9 & Not reported & 2.4 \\
\hline & & & Blind & 2.7 & 81.2 & 1.8 & 6.1 & Not reported & 3.0 \\
\hline \multirow[t]{4}{*}{ Maldives [22] } & \multirow[t]{4}{*}{2017} & \multirow{4}{*}{$\begin{array}{l}\text { RAAB, entire country } \\
62 \text { clusters, } \\
50+\text { years; } 3020 \text { people }\end{array}$} & Mild & NA & NA & NA & NA & Not reported & NA \\
\hline & & & Moderate & 50.9 & 36.3 & 0.3 & 8.0 & Not reported & 11.4 \\
\hline & & & Severe & 1.5 & 64.6 & 3.1 & 19.6 & Not reported & 1.9 \\
\hline & & & Blind & 0.0 & 51.4 & 2.8 & 30.6 & Not reported & 2.0 \\
\hline \multirow{4}{*}{$\begin{array}{l}\text { Myanmar } \\
\text { (unpublished) }\end{array}$} & \multirow[t]{4}{*}{2016} & \multirow{4}{*}{$\begin{array}{l}\text { RAAB; } 11 \text { provinces } \\
747 \text { clusters } \\
50+\text { years; } 37,350 \text { people }\end{array}$} & Mild & NA & & & & Not reported & \\
\hline & & & Moderate & 21.1 & 67.4 & 2.9 & 1.6 & 0.5 & 12.8 \\
\hline & & & Severe & 2.4 & 86.0 & 4.9 & 1.3 & 0.1 & 3.4 \\
\hline & & & Blind & 0.0 & 72.9 & 11.7 & 4.5 & 1.6 & 2.7 \\
\hline Nepal [23] & 2012 & RAAB entire country & Mild & & & & & Not reported & \\
\hline & & 615 clusters, $50+$ years, & Moderate & NA & NA & NA & NA & Not reported & 10.6 \\
\hline & & & Severe & 9.1 & 67.7 & 2.5 & 11.3 & 0 & 5.2 \\
\hline & & & Blind & 0 & 62.2 & 5.1 & 10.3 & 0 & 2.4 \\
\hline Sri Lanka [24] & 2018 & RAAB; entire country & Mild & 81.0 & 7.9 & 0.0 & 0.8 & Not reported & 13.4 \\
\hline & & 25 districts, 68 clusters & Moderate & 64.0 & 22.9 & 0.1 & 1.3 & Not reported & 15.2 \\
\hline & & & Severe & 46.7 & 36.7 & 0.0 & 2.2 & Not reported & 1.6 \\
\hline & & & Blind & 12.5 & 66.7 & 2.1 & 7.3 & Not reported & 1.6 \\
\hline Thailand [25] & 2014 & RAAB; entire country & Mild & & & & & Not reported & \\
\hline & & 176 clusters; & Moderate & 26.7 & 60.0 & 3.2 & 2.2 & Not reported & 12.6 \\
\hline & & $\begin{array}{l}\text { people; } \\
\text { pert }\end{array}$ & Severe & 10.2 & 77.1 & 3.4 & 1.7 & Not reported & 1.3 \\
\hline & & & Blind & 4.0 & 69.7 & 4.0 & 6.1 & Not reported & 0.6 \\
\hline Timor-Leste [26] & 2017 & RAAB; entire country & Mild & & & & & Not reported & NA \\
\hline & & 67 clusters & Moderate & 32.2 & 64.4 & 0.4 & 0.4 & Not reported & 16.1 \\
\hline & & $50+$ years; 3253 peop & Severe & 1.8 & 96.4 & 0.0 & 0.0 & Not reported & 6.8 \\
\hline & & & Blind & NA & 79.4 & 5.2 & 6.2 & Not reported & 4.6 \\
\hline
\end{tabular}


Table 4 Population demographics and eye care facilities required based on the integrated people-centered eye care (IPCEC) delivery model.

\begin{tabular}{|c|c|c|c|c|c|c|}
\hline \multirow[t]{2}{*}{ Country } & \multirow{2}{*}{$\begin{array}{l}\text { Year } \\
{[28,29]}\end{array}$} & \multirow{2}{*}{$\begin{array}{l}\text { Population } \\
\text { estimated/ } \\
\text { projected }\end{array}$} & \multicolumn{4}{|l|}{ Infrastructure } \\
\hline & & & $\begin{array}{l}\text { Community eye } \\
\text { care facilities } \\
\text { (cater to } 5000 \\
\text { people) }\end{array}$ & $\begin{array}{l}\text { Primary eye } \\
\text { care facilities } \\
\text { (cater to 50,000 } \\
\text { people) }\end{array}$ & $\begin{array}{l}\text { Secondary eye } \\
\text { care facilities } \\
\text { (cater to } \\
500,000 \text { people) }\end{array}$ & $\begin{array}{l}\text { Tertiary eye } \\
\text { care facilities } \\
\text { (cater to } 5 \\
\text { million people) }\end{array}$ \\
\hline \multirow[t]{2}{*}{ Bangladesh } & 2020 & $164,689,383$ & 32,937 & 3293 & 329 & 32 \\
\hline & 2030 & $178,993,869$ & 35,798 & 3579 & 357 & 35 \\
\hline \multirow[t]{2}{*}{ Bhutan } & 2020 & 771,608 & 154 & 15 & 2 & 1 \\
\hline & 2030 & 842,667 & 168 & 16 & 2 & 1 \\
\hline \multirow[t]{2}{*}{ India } & 2020 & $1,380,004,385$ & 276,000 & 27,600 & 2760 & 276 \\
\hline & 2030 & $1,503,642,322$ & 300,728 & 30,072 & 3007 & 300 \\
\hline \multirow[t]{2}{*}{ Indonesia } & 2020 & $273,523,615$ & 54,705 & 5470 & 547 & 54 \\
\hline & 2030 & $299,198,430$ & 59,839 & 5984 & 598 & 60 \\
\hline \multirow[t]{2}{*}{ Maldives } & 2020 & 540,544 & 108 & 10 & 1 & 1 \\
\hline & 2030 & 519,348 & 104 & 10 & 1 & 1 \\
\hline \multirow[t]{2}{*}{ Myanmar } & 2020 & $54,409,800$ & 10,882 & 1088 & 108 & 11 \\
\hline & 2030 & $58,478,490$ & 11,695 & 1169 & 116 & 11 \\
\hline \multirow[t]{2}{*}{ Nepal } & 2020 & $29,136,808$ & 5827 & 582 & 58 & 5 \\
\hline & 2030 & $33,389,541$ & 6678 & 667 & 66 & 7 \\
\hline \multirow[t]{2}{*}{ Sri Lanka } & 2020 & $21,369,288$ & 4274 & 427 & 42 & 4 \\
\hline & 2030 & $22,023,018$ & 4404 & 440 & 44 & 4 \\
\hline \multirow[t]{2}{*}{ Thailand } & 2020 & $69,799,978$ & 13,960 & 1396 & 139 & 13 \\
\hline & 2030 & $70,345,542$ & 14,069 & 1406 & 140 & 14 \\
\hline \multirow[t]{2}{*}{ Timor-Leste } & 2020 & $1,318,445$ & 263 & 26 & 3 & 1 \\
\hline & 2030 & $1,574,051$ & 315 & 31 & 3 & 1 \\
\hline \multirow[t]{2}{*}{ Infrastructure total } & 2020 & - & 399,110 & 39,907 & 3692 & 398 \\
\hline & 2030 & - & 429,802 & 43,374 & 4334 & 434 \\
\hline \multirow[t]{3}{*}{ Workforce total } & 2030 & - & $\begin{array}{l}\text { Community } \\
\text { workers- } 429,802\end{array}$ & AOP- 86,748 & AOP- 60,676 & AOP- 17,360 \\
\hline & & & - & - & $\begin{array}{l}\text { Comp Ophthal- } \\
8668\end{array}$ & $\begin{array}{l}\text { Comp } \\
\text { Ophthal-1736 }\end{array}$ \\
\hline & & & - & - & - & $\begin{array}{l}\text { Specialist } \\
\text { Ophthal- } 4340\end{array}$ \\
\hline
\end{tabular}

AOP allied ophthalmic personnel.

Eye and health care is provided in both public and private facilities. It is completely public funded in two countries (Bhutan, and Timor-Leste) and hybrid (public and private) funded in the remaining eight countries. In addition, health insurance policies are not uniform in the region. While some of the private facilities in Bangladesh, India and Nepal are not-for-profit organizations and offer free or subsidized care to economically under privileged section of the society, most private eye care facilities in the region operate for profit. Hence the stated workforce in Table 4 is mostly applicable to public eye care only. In addition, infrastructure and workforce planning based on the population only may not be practically applicable to some of the countries in the region. This is particularly applies to hilly and forest areas in Bhutan (70\% forest) and Nepal
(68\% hills); and archipelago of Indonesia (18,307 islands) and Maldives (1200 islands). In addition, certain smaller countries (Bhutan, Maldives) or newly emerged countries (Timor-Leste) do not have a strong base to train required number of eye health personnel including optometrists and ophthalmologists.

Two additional elements are required to make the IPCEC model robust. One, the adoption of electronic medical records (EMR) in the health systems to connect different levels of care seamlessly and two, the introduction of artificial intelligence (AI) that could empower people and eye health personnel at community and primary care level. EMR is transformative, reduces medical errors and is cost effective [39, 40]. AI using deep learning for detecting ophthalmic disorders is a new tool that could address the 
Table 5 Suggested structured integrated people-centered eye care (IPCEC) delivery of care for few ophthalmic disorders.

\begin{tabular}{|c|c|c|c|c|}
\hline Ophthalmic condition & $\begin{array}{l}\text { Community } \\
\text { eye care }\end{array}$ & $\begin{array}{l}\text { Primary } \\
\text { eye care }\end{array}$ & Secondary care & Tertiary care \\
\hline $\begin{array}{l}\text { Uncorrected } \\
\text { refractive error }\end{array}$ & $\begin{array}{l}\text { Screening } \\
\text { Advocacy }\end{array}$ & $\begin{array}{l}\text { Adult refraction } \\
\text { dispensing }\end{array}$ & $\begin{array}{l}\text { Children Refraction } \\
\text { Dispensing }\end{array}$ & $\begin{array}{l}\text { Amblyopia therapy } \\
\text { Contact lens } \\
\text { Refractive surgery }\end{array}$ \\
\hline Cataract & Advocacy & Detect \& refer & Surgery & $\begin{array}{l}\text { Complicated cataract } \\
\text { surgery }\end{array}$ \\
\hline $\begin{array}{l}\text { Glaucoma } \\
\text { Diabetic retinopathy }\end{array}$ & & & $\begin{array}{l}\text { Detect, Confirmation } \\
\text { Medical care }\end{array}$ & Surgery \\
\hline Corneal Infection & $\begin{array}{l}\text { Advocacy } \\
\text { Preventive } \\
\text { treatment }\end{array}$ & $\begin{array}{l}\text { Detect } \\
\text { preventive } \\
\text { treatment } \\
\text { Refer }\end{array}$ & & \\
\hline
\end{tabular}

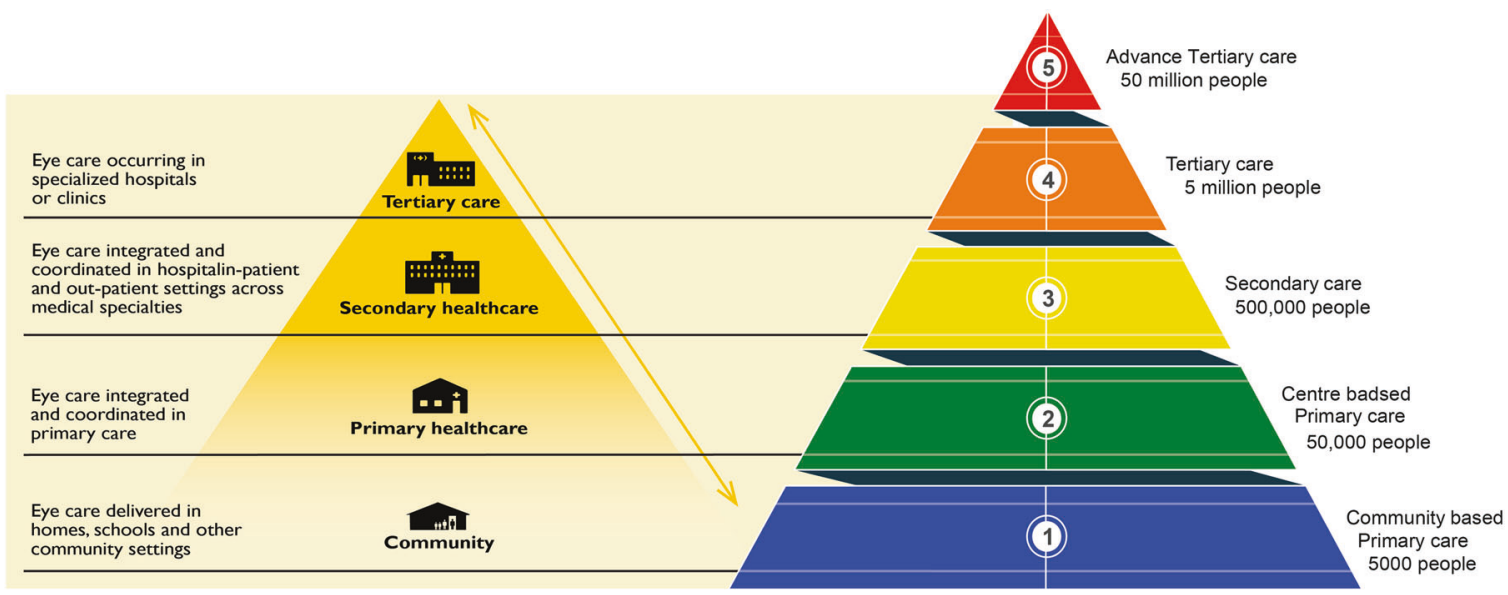

Fig. 1 Eye health delivery structure: comparison and similarity between the World Report on Vision recommended and LV Prasad Eye Institute (Hyderabad, India) practiced eye health pyramid.

gap in skilled workforce and geographical distances, to some extent. One example where AI has been proven as a good clinical decision tool is the grading of retinal images of people with diabetic retinopathy guiding immediate or deferred referral to ophthalmologists. As it has been validated in various data sets, it is beginning to be implemented into clinical practice [41-43]. Research in AI has also extended beyond the fundus photograph to optical coherence tomography and visual field so that it can be used in several other ophthalmic disorders including glaucoma [44].

Realizing the benefits of delivery of primary eye care through Vision Centers (serving 50,000 people), a model developed by the L V Prasad Eye Institute [12, 45] many NGOs have been establishing stand-alone Vision Centers in Bangladesh, India and Nepal. A vertical eye care programme largely helps the country achieve a higher target though integration within the general health system at different levels of care has the potential to attain universal eye health coverage faster. In LMIC, there is an overlap between traditional eye disorders such as uncorrected refractive error and un-operated cataract with noncommunicable diseases (NCD) including diabetic retinopathy and age-related macular degeneration, and neglected tropical disease (NTD) such as trachoma and onchocerciasis [31]. Responding to the challenges of NCDs and NTDs will require system re-thinking, analysis and action [46].

The characteristics essential to quality health-care services include being effective, safe and people-centered, and also being timely, equitable, integrated and efficient [1]. The UHC could be measured by two key performance indicators: (a) the proportion of a population that can access essential quality health services and (b) proportion of the population that spends a significant amount of household income on health. There is a global commitment of the 193member states of the United Nations to achieve UHC by 2030 [47]. All partners need to recognize that achieving UHC requires coordinated efforts across multiple sectors, development of strong, sustainable and equitable health systems and regional cooperation that help to improve health outcomes. 


\section{Summary}

\section{What was known before}

- The VLEG of the GBD has published the burden of eye disease from 1990 to predictions for 2020.

- Ten countries in the WHO SEA region have completed RAAB studies in the elderly population and seven of them have published their data between 2012 and 2019.

\section{What does this study add}

- Unpublished completed RAAB data from three countries of the WHO SEA region were added to the analysis.

- The population estimates of 2030 were used to enumerate essential eye care facilities.

- The estimation of workforce was made by the recommendations of the WRV- the IPCEC delivery model and the eye health pyramid used in India.

Acknowledgements Dr Aldian Halim, Mr Yuddha D Sapkota and Prof. Praveen Vashist shared unpublished data of recently conducted RAAB at Indonesia, Myanmar and India, respectively.

Funding Hyderabad Eye Research Foundation, Hyderabad, India Ornate India GCRF UKRI funding (Grant no.: MR/P207881/1), UK.

\section{Compliance with ethical standards}

Conflict of interest The authors declare that they have no conflict of interest.

Publisher's note Springer Nature remains neutral with regard to jurisdictional claims in published maps and institutional affiliations.

\section{References}

1. World Report on Vision. https://www.who.int. Accessed Dec 2019.

2. Framework on Integrated people-centred health services. https://www.who.int/areas/people-centred-care. Accessed Dec 2019.

3. Universal Health Coverage. https://www.who.int. Accessed Dec 2019.

4. Raid SF, Dart JKG, Cooling RJ. Primary care and ophthalmology in the United Kingdom. Br J Ophthalmol. 2003;87:493-99.

5. Rao GN. The Barrie Jones lecture- Eye care for the neglected population: changes and solutions. Eye. 2015;29:3-45.

6. Global Burden of Disease (GBD). http://www.healthdata.org/gbd. Accessed Jan 2020.

7. Metrics: disability-adjusted life year (DALY)- WHO. https:// www.who.int/healthinfo/global_burden_disease. Acccessed Dec 2019.

8. Global burden of disease-IAPB. https://www.iapb.org/tag/globalburden-of-disease. Accessed Jan 2020.
9. A rapid survey methodology to provide data on prevalence and causes of visual loss. International Centre for Eye Health. www.ceh.Ishtm.ac.uk. Accessed Jan 2020.

10. Blindness and vision impairment- World Health Organization. http://www.who.int. Accessed Jan 2020.

11. Comprehensive primary healthcare through health and wellness centre. http://www.nhsrcindia.org. Accessed Dec 2019.

12. Rao GN, Khanna RC, Athota SM, Rajshekar V, Rani PK. Integrated model of primary and secondary eye care for underserved rural areas: the L V Prasad Eye Institute experience. Indian J Ophthalmol. 2012;60:396-400.

13. Das T, Panda L. Imagining eye care in India (2018 LP Agarwal lecture) Indian. J Ophthalmol. 2018;66:1532-38.

14. Steven G, White R, Flaxman SR, Price H, Jonas JB, Keeffe J, et al. Global prevalence of vision impairment and blindness: magnitude and temporal trends, 1990-2010. Ophthalmology. 2013;120:2377-84.

15. Bourne RRA, Flaxman SR, Braithwaite T, Cicinelli MV, Das A, Jonas JB, et al. Magnitude, temporal trends, and projections of the global prevalence of blindness and distance and near vision impairment: a systemic review and meta-analysis. Lancet Glob Health. 2017;109x:130302-9. https://doi.org/10.1016/S2214109X(17)30293-0.

16. Jonas JB, George R, Asokan R, Flaxman SR, Keeffe J, Leasher J, et al. Prevalence and causes of vision loss in Central and South Asia: 1990-2010. Br J Ophthalmol. 2014;98:592-98.

17. Nangia V, Jonas JB, George R, Lingam V, Ellwein L, Cicineli $\mathrm{MV}$, et al. Prevalence and causes of blindness and vision impairment: magnitude, temporal trends and projections in South and Central Asia. Br J Ophthalmol. 2019;103:871-77.https://doi. org/10.1136/bjophthalmol-2018-312292.

18. Keeffe J, Taylor HR, Fotis K, Pesudovs K, Flaxman SR, Jonas JB, et al. Prevalence and causes of vision loss in Southeast Asia and Oceania: 1990-2010. Br J Ophthalmol 2014;98:586-91. https://doi.org/10.1136/bjophthalmol-2013-304050.

19. Keeffe JE, Casson RJ, Pesudovs K, Taylor HR, Cicinelli MV, Das A, et al. Prevalence and causes of vision loss in South-east Asia and Oceania in 2015: magnitude, temporal trends and projections. Br J Ophthalmol. 2019;103:878-84. https://doi.org/10.1136/ bjophthalmol-2018-311946.

20. Muhit M, Wadud Z, Islam J, Khair Z, Shamana BR, Jung J, et al. Generating evidence for program planning rapid assessment of avoidable blindness in Bangladesh. Ophthalmic Epidemiolol. 2016;23:176-84.

21. Lepcha NR, Sharma IP, Sapkota YD, Das T, Phuntsho T, Tenzin $\mathrm{N}$, et al. Changing trends of blindness, visual impairment and cataract surgery in Bhutan: 2009-2018. PLoS ONE. 2019;14: e0216398. https://doi.org/10.1371/journalpone.0216398.

22. Thoufeeq U, Das T, Limburg H, Maharshi M, Panda L, Sil A, et al. First rapid assessment of avoidable blindness (RAAB) survey in Maldives: prevalence and causes of blindness and cataract surgery. Asia Pac J Ophthalmol. 2017;7:316-20.

23. Epidemiology of blindness in Nepal. https://www.iapb.org/wpcontent/uploads/Epidemiology-of-Blindness-Nepal.pdf. Accessed Jan 2020.

24. Banagala C, Gilbert C, Murthy GVS, Schmidt E, Mahipala PG, Edussuriya K, Sri Lanka National Blindness, Visual Impairment and Disability Steering Committee and Survey Team et al. Prevalence, causes, magnitude and risk factors of visual impairment and blindness in Sri Lanka. Ceylon Med J. 2018;63:s10-17. https://doi.org/10.4038/cmj.v63i5.8736.

25. Isipradt $S$, Sirimaharj $M$, Charukamnoethanok $P$, Thonginneta $O$, Wongsawad W, Sathornsumette B, et al. The first rapid assessment of avoidable blindness (RAAB) in Thailand. PLoS ONE. 2014. https://doi.org/10.1371/journal.pone.0114245. 
26. Correia M, Das T, Mango J, Pereira BM, Andrade V, Limburg H, et al. Prevalence and causes of blindness, visual impairment and cataract surgery in Timor-Leste. Clin Ophthalmol. 2017;11:2125-31.

27. Nepal: first country in South-East Asia validated for eliminating trachoma. https://www.who.int/neglected_diseases. Accessed Jan 2020.

28. www.worldometer.info. Assessed Jan 2020.

29. populationpyramid.net. Assessed Jan 2020.

30. Foster A, Resnikof S. The impact of Vision 2020 on global blindness. Eye. 2005;19:1133-35.

31. Ackland P. The accomplishments of the global initiatives VISION 2020: the Right to Sight and the focus for the next 8 years of the campaign. Indian J Ophthalmol. 2012;60:38-86.

32. Flaxman SR, Bourne RRA, Resnikoff S, Ackland P, Braithwaite $\mathrm{T}$, Cicinelli MV, et al. Global cause of blindness and distance vision impairment 1990-2020: a systematic review and metaanalysis. Lancet Glob Health.2017;5:e1221-34. https://doi.org/10. 1016/S2214-109X(17)30393S-5.

33. Ramke J, Gilbert CE. Universal eye health: are we getting closer? Lancet Global Health. 2017. https://doi.org/10.1016/S2214109x (17)30292-9.

34. Vision Atlas. atlas.iapb.org. Accessed Dec 2019.

35. Sapkota YD. Human resources for eye health in South Asia. Community Eye Health. 2018;31:s1-2.

36. Das T, Ackland P, Correia M, Hanutsaha P, Mahipala P, Nukella PB, IAPB South East Asia Region Eye Health Study Group et al. Is the 2015 eye care service delivery profile in Southeast Asia closer to universal eye health need!. Int Ophthalmol. 2018;38: 469-80. https://doi.org/10.1007/s10792-017-0481y.
37. WHO/HIS/SDS/2015.6. http://www.who.int. Accessed Dec 2019.

38. Comprehensive primary healthcare through health and wellness centre. http://www.nhsrcindia.org. Accessed Dec 2019.

39. Wang SJ, Middleton B, Prosser LA, Bardon CG, Spurr CD, Carchidi PJ, et al. A cost-benefit analysis of electronic medical records in primary care. Am J Med. 2003;114:397-403.

40. Hillestad R, Bigelow J, Bower A, Girosi F, Meili R, Scoville R, et al. Can electronic medical record systems transform health care? Potential health benefits, savings, and costs. Health Aff. 2005;24:1103-17. https://doi.org/10.1377/hlthaff.24.5.1103.

41. Gulson V, Peng LH, Coram M, Stumpe MC, Wu DJ, Narayanaswamy A, et al. Development and validation of a deep learning algorithm for detection of diabetic retinopathy in retinal fundus photographs. JAMA. 2016;316:2402-10.

42. Wong TY, Bressler NM. Artificial intelligence with deep learning technology looks into diabetic retinopathy screening. JAMA. 2016;316:2366-67.

43. Beam AL, Kohane IS. Translating artificial intelligence into clinical care. JAMA. 2016;316:2368-9.

44. Ting DSW, Pasquale LR, Peng L, Campbell JP, Lee AY, Raman $\mathrm{R}$. Artificial intelligence and deep learning in ophthalmology. Br J Ophthalmol. 2019;103:167-75.

45. Misra V, Vashist P, Malhotra S, Gupta SK. Models of primary eye care services in India. Indian J Com Med. 2015;40:79-84.

46. Blanchet K, Gilbert C, de Savigny D. Rethinking eye health systems to achieve universal coverage: the role of research. Br J Ophthalmol. 2014;98:1325-8.

47. UHC 2030- Accelerating progress towards Universal Health. https://www.uhc2030.org. Accessed Dec 2019. 